COMUNICAÇÃO CIENTÍFICA

\title{
AMIDO DE MILHO E HIPOCLORITO DE SÓDIO NO ENRAIZAMENTO IN VITRO DO ABACAXIZEIRO VITÓRIA E SEU EFEITO NA ACLIMATIZAÇÃO' ${ }^{1}$
}

\author{
MONIQUE RODRIGUES PEREIRA², VIRGINIA SILVA CARVALHO ${ }^{3}$, \\ ELIZABETH DE FÁTIMA LUCAS ${ }^{4}$, GERALDO DE AMARAL GRAVINA ${ }^{5}$
}

RESUMO-Este trabalho objetivou reduzir o custo de produção dos meios de cultura pela substituição do ágar por amido de milho e da esterilização física em autoclave pela esterilização química com hipoclorito de sódio $(\mathrm{NaClO})$ em mudas de abacaxizeiro 'Vitória' propagadas in vitro. As brotações foram transferidas para meio de enraizamento composto pelos sais de MS, vitaminas de White, mioinositol e sacarose. O experimento foi instalado em DIC, em fatorial $3 \times 2$ : meios geleificados com ágar $\left(6,0 \mathrm{~g} \mathrm{~L}^{-1}\right)$, amido de milho $\left(60,0 \mathrm{~g} \mathrm{~L}^{-1}\right)$ e ágar $\left(3,0 \mathrm{~g} \mathrm{~L}^{-1}\right)+$ amido de milho $\left(30,0 \mathrm{~g} \mathrm{~L}^{-1}\right)$, esterilizados em autoclave ou quimicamente com a fervura do meio e uso de $\mathrm{NaClO}$ a $0,05 \%$ para enxaguar a vidraria. Após um mês de enraizamento in vitro, parte das mudas foi avaliada quanto ao número de folhas e de raízes, e massas das matérias fresca e seca. O restante foi aclimatizado por 90 dias em casa de vegetação, ao final dos quais foram avaliados número de folhas, número de raízes, massa da matéria fresca e seca da parte aérea, raízes e total, área foliar, altura e diâmetro da roseta. A fervura do meio + esterilização química das vidrarias não diferiu da autoclavagem para a maioria dos parâmetros avaliados, enquanto o amido de milho proporcionou melhor desenvolvimento das mudas, tanto in vitro quanto durante a aclimatização.

Termos para indexação: ágar, agente geleificante, autoclavagem, esterilização química.

\section{CORN STARCH AND SODIUM HYPOCHLORITE ON IN VITRO ROOTING OF PINEAPPLE 'VITÓRIA' AND THEIR EFFECT ON ACCLIMATIZATION}

\begin{abstract}
This study aimed to reduce the production cost of culture media for agar substitution by corn starch and physical sterilization in autoclave by chemical sterilization with sodium hypochlorite $(\mathrm{NaClO})$ in the plantlets of pineapple 'Vitória' propagated in vitro. The shoots were transferred to rooting medium composed of MS salts, White's vitamins, myo-inositol and sucrose. The experiment was conducted in a completely randomized design in a factorial $3 \times 2$ : media jellified with agar $\left(6,0 \mathrm{~g} \mathrm{~L}^{-1}\right)$, corn starch $\left(60,0 \mathrm{~g} \mathrm{~L}^{-1}\right)$ and agar $\left(3,0 \mathrm{~g} \mathrm{~L}^{-1}\right)+$ corn starch $\left(30,0 \mathrm{~g} \mathrm{~L}^{-1}\right)$, sterilized in autoclave or chemically boiling the medium and use of $0,05 \% \mathrm{NaClO}$ to rinse the glassware. After a month of in vitro rooting, part of the plants were evaluated for number of leaves and roots and masses of fresh and dry materials. The rest of the plantlets was acclimatized for 90 days in a greenhouse. At the end of this period number of leaves, number of roots, fresh weight and dry weight of aerial part, root and total; leaf area, height and diameter of rosette were evaluated. The boiling + chemical sterilization did not differ of autoclave sterilization for the majority of parameters, while the corn starch enhanced growth of plantlets both in vitro and during acclimatization. Index terms: agar, autoclaving, chemical sterilization, gelling agent.
\end{abstract}

${ }^{1}$ (Trabalho 122-14). Recebido em: 01-04-2014. Aceito para publicação em: 22-10-2014. Trabalho de conclusão de curso da primeira autora. UENF

${ }^{2}$ Engenheira Agrônoma UENF/CCTA/LFIT. E-mail: moniquerodriguesp@yahoo.com.br

${ }^{3}$ Dra. em Fitotecnia, Professora Associada UENF/CCTA/LFIT. E-mail: virginia@uenf.br

${ }^{4}$ Tecnóloga em Horticultura, Bolsista de Extensão UENF/CCTA/LFIT. E-mail: bethdefatima@gmail.com

${ }^{5}$ Dr. em Fitotecnia, Professor Associado UENF/CCTA/LEAG. E-mail: gravina@uenf.br 
O abacaxizeiro (Ananas comosus var. comosus) representa uma das frutíferas mais importantes no agronegócio mundial, sendo que, em 2012, Filipinas, Brasil, Costa Rica, Tailândia, China e Índia alcançaram destaque na produção mundial do fruto (FAO, 2013). No Brasil, a abacaxicultura ocupa uma área de 80.582 ha, com maior concentração nas regiões Nordeste e Sudeste, (IBGE, 2013).

A cultivar Vitória, fruto do cruzamento dos abacaxizeiros Primavera e Smooth Cayenne, possui diversas características que a tornam bastante aceita, tanto pelos consumidores como pelos produtores. Entre elas, destacam-se o elevado vigor das plantas; a semelhança ou até mesmo a superioridade agronômica em relação às cultivares mais plantadas no Brasil; a ausência de espinhos nas folhas, facilitando o manejo no campo; o bom perfilhamento e a resistência à fusariose, que constitui um dos maiores problemas fitossanitários da cultura (VENTURA et al., 2006).

Convencionalmente, o abacaxizeiro é propagado vegetativamente por meio de mudas, como rebentão, filhote rebentão, filhote e coroa, que se desenvolvem na planta, e, por este motivo, as lavouras de abacaxi, em quase sua totalidade, utilizam material propagativo do próprio campo, podendo favorecer a disseminação de doenças e patógenos, o que acarreta em perdas e redução na produção (REINHARDT; CUNHA, 2006).

Outra forma de multiplicar o abacaxizeiro é por meio da utilização de técnicas de cultura de tecidos vegetais, que possibilita a produção em larga escala de clones de plantas- matrizes em meio de cultivo asséptico, sob condições controladas de temperatura e luminosidade (TEIXEIRA et al., 2006). Contudo, devido a diversos fatores, as mudas micropropagadas são mais caras que as convencionais, o que dificulta sua adoção por grande parte dos produtores (SOUZA; JUNGHANS, 2006).

Diversos trabalhos têm sido realizados visando à redução de custos do processo de micropropagação, incluindo formas alternativas de preparo dos meios de cultivo utilizados, que contribuem para elevar o preço final das mudas. Polissacarídeos alternativos ao ágar, como os amidos de milho e mandioca, têm sido testados com sucesso em algumas culturas, sobretudo na fase de enraizamento in vitro (FERRI et al., 1998; ERIG et al., 2004; PEREIRA, 2011; OLIVEIRA, 2012). Além disso, a esterilização química do meio de cultivo e dos utensílios, com solução de hipoclorito de sódio, demonstra ser uma técnica eficiente, podendo substituir a esterilização física realizada em autoclaves, que são equipamentos caros e com alto consumo de energia elétrica (TEIXEIRA et al., 2006; RIBEIRO; TEIXEIRA, 2007; SAWANT; TAWAR, 2011; PEREIRA, 2011; TIWARI et al., 2012; OLIVEIRA, 2012).

O presente trabalho objetivou avaliar o crescimento de plantas de abacaxizeiro 'Vitória' cultivadas na fase de enraizamento, em meios de cultivo geleificados com ágar, amido de milho ou ágar + amido de milho, e esterilizados fisicamente ou por fervura do meio + esterilização química dos frascos.

O experimento foi realizado na Universidade Estadual do Norte Fluminense Darcy Ribeiro UENF, localizada em Campos dos Goytacazes - RJ. O município está situado na latitude $21^{\circ} 45^{\prime} \mathrm{S}$ e na longitude $41^{\circ} 20^{\prime} \mathrm{W}$ e possui altitude média de 11 metros. A etapa in vitro e a aclimatização foram realizadas no Setor de Horticultura do Laboratório de Fitotecnia. O delineamento foi o inteiramente casualizado, com dois fatores. Após a realização de diversos ensaios preliminares, foram definidas as seguintes combinações de agentes geleificantes: Ágar Bacteriológico $\operatorname{Vetec}^{\circledR}\left(6,0 \mathrm{~g} \mathrm{~L}^{-1}\right)$; Amido de Milho Maizena ${ }^{\circledR}\left(60 \mathrm{~g} \mathrm{~L}^{-1}\right)$ e Amido de Milho (30 $\left.\mathrm{g} \mathrm{L}^{-1}\right)+$ Ágar $\left(3,0 \mathrm{~g} \mathrm{~L}^{-1}\right)$. Na esterilização dos meios e vidrarias, foram usados dois processos: autoclavagem a $1,2 \mathrm{Kgf} . \mathrm{cm}^{2}$ e $121^{\circ} \mathrm{C}$, por 20 minutos, e química por meio do enxágue da vidraria em solução de $\mathrm{NaClO} 0,05 \%$. O experimento contou com 10 repetições, sendo a unidade experimental um frasco contendo cinco brotações, totalizando 50 brotações por tratamento. Sob condições assépticas, foram colocadas cinco brotações por frasco com o meio de enraizamento.

As brotações de abacaxizeiro 'Vitória' foram provenientes do Laboratório Biomudas, situado em Venda Nova do Imigrante - ES, e estavam no quinto e último subcultivo, em meio de multiplicação composto pelos sais de MS e vitaminas de White (MURASHIGE; SKOOG, 1962), $30 \mathrm{~g} \mathrm{~L}^{-1}$ de sacarose, $100 \mathrm{mg} \mathrm{L}^{-1}$ de mioinositol e $11,10 \mu \mathrm{mol} \mathrm{L}^{-1}$ de BA (benziladenina).

O meio de cultivo utilizado foi constituído pelos sais de MS e vitaminas de White (MURASHIGE; SKOOG, 1962), $30 \mathrm{~g} \mathrm{~L}^{-1}$ de sacarose e $100 \mathrm{mg} \mathrm{L}^{-1}$ de mioinositol. Toda a etapa de esterilização química foi conduzida em câmara de fluxo laminar. Os frascos foram enxaguados na solução de $\mathrm{NaClO}$ e, após a fervura em micro-ondas, foram vertidos $40 \mathrm{~mL}$ de meio de cultivo em cada frasco. Os frascos foram mantidos em temperatura de $27 \pm 2{ }^{\circ} \mathrm{C}$, durante uma semana, antes da inoculação dos explantes, para verificar a presença de contaminantes. Em seguida, os frascos com as brotações foram mantidos por 30 
dias em sala de cultivo, à temperatura de $27 \pm 2^{\circ} \mathrm{C}$, e irradiância de $25 \mu \mathrm{mol} \mathrm{m} \mathrm{m}^{-2} \mathrm{~s}^{-1}$, fornecida por lâmpadas florescentes $\left(\mathrm{OSRAM}^{\circledR}\right.$, luz do dia) e fotoperíodo de 16 h 8 (luz:escuro). Após este período, foram avaliados número de folhas e de raízes, massas das matérias fresca e seca, em metade das mudas (25) de cada tratamento.

Após a etapa in vitro, as outras 25 mudas foram aclimatizadas em casa de vegetação com cobertura de plástico $(100 \mu \mathrm{m})$ e $50 \%$ de sombreamento, no período de fevereiro a abril de 2011. O plantio foi feito em bandejas de poliestireno expandido, de 128 células, com aproximadamente $25 \mathrm{~cm}^{2}$ por célula, com o substrato Basaplant ${ }^{\circledR}$ Hortaliças. A etapa de aclimatização seguiu o mesmo delineamento e esquema fatorial da parte in vitro, com 25 repetições. Cada planta constituiu uma repetição. Antes do plantio, as mudas foram lavadas em água corrente para a retirada do meio de cultivo aderido às raízes. Foram realizadas adubações quinzenais com três mililitros por planta da solução nutritiva de Hoagland e Arnon (RESH, 1997). As plantas foram irrigadas diariamente por aspersão.

Após noventa dias de aclimatização, foram avaliados: número de folhas, altura e diâmetro da roseta, área foliar, massas das matérias fresca e seca da parte aérea, da raiz e total.

Os dados foram submetidos aos testes de Lilliefors e Bartlett para a verificação da normalidade dos dados e homogeneidade de variâncias entre os tratamentos. Em seguida, foram submetidos à Análise de Variância (ANOVA), e as médias foram comparadas pelo teste de Tukey, a $5 \%$ de probabilidade, utilizando o programa Genes ${ }^{\circledR}$ (CRUZ, 2006).

As brotações apresentaram 100\% de sobrevivência nas condições in vitro. Para massa da matéria fresca e número de raízes, a esterilização química foi inferior à física nos meios geleificados com amido de milho, não diferindo para os demais agentes. Na esterilização química, não houve diferença significativa entre os agentes geleificantes para a maioria dos parâmetros, exceto para o número de folhas. Já entre os meios autoclavados, o amido de milho não diferiu do ágar (controle) (Tabela 1). Para número de folhas, não houve diferença entre as duas formas de esterilização, bem como entre os agentes geleificantes nos meios esterilizados fisicamente; contudo, na fervura do meio + esterilização química das vidrarias, o amido de milho foi estatisticamente igual ao ágar (Tabela 1). Para massa da matéria seca, a esterilização física foi inferior à fervura do meio + esterilização química das vidrarias no meio geleificado com ágar; porém, entre os demais agentes geleificantes, não houve diferença entre as esterilizações. Para este parâmetro, os agentes geleificantes, não diferiram entre si (Tabela 1).

Após 90 dias de aclimatização, observou-se que o uso do amido de milho associado à fervura do meio + esterilização química da vidraria, do meio de cultivo, proporcionou resultados inferiores àqueles dos meios autoclavados para os parâmetros número de folhas, área foliar, massa da matéria fresca e seca da parte aérea e total, não diferindo nos demais (Tabela 2). Entre os agentes geleificantes, é possível observar que, para a maioria dos parâmetros, as plantas oriundas dos meios com amido de milho puro ou em combinação com ágar apresentaram comportamento semelhante ou superior àquelas dos meios geleificados com ágar.

De modo geral, a fervura do meio + esterilização química das vidrarias com $\mathrm{NaClO}$ foi semelhante ou superior à autoclavagem. Nos casos em que foi inferior, a esterilização química estava associada à geleificação com amido de milho puro. Esses resultados confirmam aqueles obtidos por Teixeira et al. (2006), que obtiveram sucesso na esterilização do meio de cultivo para multiplicação de Ananas comosus cv. Smooth Cayenne com a utilização de $\mathrm{NaClO}$. Trabalhando com Sequoia sempervirens, Ribeiro e Teixeira (2007) também alcançaram resultados positivos utilizando concentrações de $\mathrm{NaClO}$ entre 0,003 e $0,004 \%$. No cultivo in vitro de Eucalyptus pellita, Teixeira et al. (2008) obtiveram 100\% de esterilização dos meios de cultivo utilizando $0,005 \%$ de $\mathrm{NaClO}$. Sawant e Tawar (2011) e Tiwari et al. (2012), todos trabalhando com Saccharum officinarum, também conseguiram completa assepsia do meio de cultivo usando o $\mathrm{NaClO}$ como agente químico esterilizante.

Foi possível observar que as plantas cultivadas em meio com amido de milho apresentaram desenvolvimento semelhante àquelas oriundas dos meios geleificados com ágar, enquanto a combinação ágar + amido de milho ocasionou resultados inferiores ao amido de milho puro, não diferindo do ágar. Esses resultados sugerem que o amido usado de forma isolada pode substituir, satisfatoriamente, o ágar na geleificação de meios de cultivo para o enraizamento do abacaxizeiro 'Vitória' e, assim, contribuir para redução de custos do meio de cultura, uma vez que o ágar é o componente do meio de maior custo.

Costa et al. (2007), trabalhando com estabelecimento e multiplicação in vitro de Ananas comosus 'Quinari' e 'Rio Branco', relataram que o amido de mandioca foi eficiente na geleificação do meio de cultivo, além de proporcionar bons 
resultados quanto ao desenvolvimento dos explantes. $\mathrm{O}$ uso do amido de milho isolado ou em combinação com o ágar mostrou-se eficaz para a multiplicação in vitro de Malus domestica BORKH cv. Galaxy (ERIG et al., 2004). Ainda trabalhando com macieira, Ferri et al. (1998) verificaram que a substituição parcial do ágar por amido de mandioca favoreceu o enraizamento in vitro das brotações.

A partir dos resultados encontrados neste trabalho, conclui-se que:
- O uso do amido de milho em substituição ao ágar como agente geleificante do meio de cultivo proporcionou melhor desenvolvimento das mudas, tanto in vitro quanto na aclimatização.

- É possível utilizar o amido de milho como agente geleificante do meio de cultivo para o enraizamento in vitro de abacaxizeiro 'Vitória', bem como substituir a autoclavagem pela esterilização química com $\mathrm{NaClO}$.

TABELA 1- Análises biométricas de mudas de abacaxizeiro 'Vitória' após um mês de enraizamento in vitro. Campos dos Goytacazes - RJ, 2011.

\begin{tabular}{|c|c|c|c|c|c|c|}
\hline \multirow{2}{*}{ Agente Geleificante } & \multicolumn{2}{|c|}{ Número de Folhas } & \multirow{2}{*}{ Média- } & \multicolumn{2}{|c|}{ Número de Raízes } & \multirow{2}{*}{ Média } \\
\hline & $\mathrm{EF}$ & EQ & & $\mathrm{EF}$ & EQ & \\
\hline Ágar & $12,54 \mathrm{~A} \mathrm{a}$ & $12,77 \mathrm{~A} \mathrm{a}$ & 12,65 & $2,20 \mathrm{~A} \mathrm{ab}$ & $1,41 \mathrm{~A} \mathrm{a}$ & 1,81 \\
\hline Amido de milho & $10,60 \mathrm{~A} \mathrm{a}$ & $11,76 \mathrm{~A} \mathrm{ab}$ & 11,18 & $2,96 \mathrm{~A} \mathrm{a}$ & $0,71 \mathrm{~B} \mathrm{a}$ & 1,84 \\
\hline Ágar + Amido de Milho & $11,66 \mathrm{~A} \mathrm{a}$ & $10,20 \mathrm{~A} \mathrm{~b}$ & 10,93 & $2,00 \mathrm{~A} \mathrm{~b}$ & $1,42 \mathrm{~A} \mathrm{a}$ & 1,71 \\
\hline Média & 11,60 & 11,57 & & 2,38 & 1,18 & \\
\hline $\mathrm{CV}(\%)$ & & & & & & \\
\hline \multirow[t]{2}{*}{ Agente Geleificante } & \multicolumn{2}{|c|}{$\begin{array}{c}\text { Massa da Matéria Fresca Total } \\
(\mathrm{g})\end{array}$} & Média & \multicolumn{2}{|c|}{$\begin{array}{c}\text { Massa da Matéria Seca Total } \\
(\mathrm{g})\end{array}$} & \multirow[t]{2}{*}{ Média } \\
\hline & $\mathrm{EF}$ & EQ & & $\mathrm{EF}$ & EQ & \\
\hline Ágar & $0,31 \mathrm{~A} \mathrm{ab}$ & $0,32 \mathrm{~A} \mathrm{a}$ & 0,32 & $0,024 \mathrm{~B} \mathrm{a}$ & $0,044 \mathrm{~A} \mathrm{a}$ & 0,034 \\
\hline Amido de milho & $0,40 \mathrm{~A} \mathrm{a}$ & $0,26 \mathrm{~B} \mathrm{a}$ & 0,33 & $0,029 \mathrm{~A} \mathrm{a}$ & $0,022 \mathrm{~A} \mathrm{a}$ & 0,025 \\
\hline Ágar + Amido de Milho & $0,23 \mathrm{~A} \mathrm{~b}$ & $0,26 \mathrm{~A} \mathrm{a}$ & 0,25 & $0,029 \mathrm{~A} \mathrm{a}$ & $0,022 \mathrm{~A} \mathrm{a}$ & 0,025 \\
\hline Média & 0,31 & 0,28 & & 0,027 & 0,029 & \\
\hline $\mathrm{CV}(\%)$ & \multicolumn{2}{|c|}{33,93} & \multicolumn{4}{|c|}{49,09} \\
\hline
\end{tabular}

Médias seguidas pelas mesmas letras maiúsculas na horizontal e minúsculas na vertical não diferem entre si, pelo teste de Tukey, a 5\% de probabilidade. EF: esterilização física; EQ: esterilização química. 
TABELA 2. Análises biométricas de mudas de abacaxizeiro 'Vitória' oriundas de cultivo in vitro após 90 dias de aclimatização em casa de vegetação. Campos dos Goytacazes - RJ, 2011.

\begin{tabular}{|c|c|c|c|c|c|c|}
\hline \multirow{2}{*}{ Agente Geleificante } & \multicolumn{2}{|c|}{ Número de Folhas } & \multirow{2}{*}{-Média- } & \multicolumn{2}{|c|}{ Área Foliar $\left(\mathrm{cm}^{2}\right)$} & \multirow{2}{*}{ Média } \\
\hline & $\mathrm{EF}$ & EQ & & $\mathrm{EF}$ & EQ & \\
\hline Ágar & $10,80 \mathrm{~A} \mathrm{~b}$ & $11,70 \mathrm{~A} \mathrm{a}$ & 11,25 & $22,31 \mathrm{~A} \mathrm{ab}$ & $22,39 \mathrm{~A} \mathrm{a}$ & 22,35 \\
\hline Amido de milho & $13,60 \mathrm{~A} \mathrm{a}$ & $11,00 \mathrm{~B} \mathrm{a}$ & 12,30 & $28,02 \mathrm{~A} \mathrm{a}$ & $17,79 \mathrm{~B} \mathrm{a}$ & 22,91 \\
\hline Ágar + Amido de Milho & $10,70 \mathrm{~A} \mathrm{~b}$ & $12,10 \mathrm{~A} \mathrm{a}$ & 11,4 & $19,34 \mathrm{~A} \mathrm{~b}$ & $23,68 \mathrm{~A} \mathrm{a}$ & 21,51 \\
\hline Média & 11,70 & 11,60 & & 23,22 & 21,28 & \\
\hline $\mathrm{CV}(\%)$ & & & & & & \\
\hline \multirow{3}{*}{$\begin{array}{c}\text { Agente Geleificante } \\
\text { Ágar }\end{array}$} & \multicolumn{2}{|c|}{ Altura da Roseta $(\mathrm{cm})$} & \multicolumn{3}{|c|}{ Diâmetro da Roseta $(\mathrm{cm})$} & \multirow{3}{*}{$\begin{array}{c}\text { Média } \\
9,19\end{array}$} \\
\hline & $\mathrm{EF}$ & EQ & Média & EF & EQ & \\
\hline & $2,79 \mathrm{~A} \mathrm{a}$ & $2,75 \mathrm{~A} \mathrm{a}$ & & $7,58 \mathrm{~A} \mathrm{a}$ & $10,80 \mathrm{~A} \mathrm{~b}$ & \\
\hline Amido de milho & $2,75 \mathrm{~A} \mathrm{a}$ & $2,58 \mathrm{~A} \mathrm{a}$ & 2,66 & $8,10 \mathrm{~A} \mathrm{a}$ & $13,60 \mathrm{~A} \mathrm{a}$ & 10,85 \\
\hline Ágar + Amido de Milho & $2,18 \mathrm{~A} \mathrm{~b}$ & $2,37 \mathrm{~A} \mathrm{a}$ & 2,27 & $6,15 \mathrm{Ab}$ & $10,70 \mathrm{~A} \mathrm{~b}$ & 8,42 \\
\hline Média & 3,86 & 2,56 & & 7,27 & 11,7 & \\
\hline $\mathrm{CV}(\%)$ & & & & & & \\
\hline \multirow[t]{2}{*}{ Agente Geleificante } & \multicolumn{2}{|c|}{$\begin{array}{c}\text { Massa da Matéria Fresca Total } \\
(\mathrm{g})\end{array}$} & Média & \multicolumn{2}{|c|}{$\begin{array}{c}\text { Massa da Matéria Seca da } \\
\text { Parte Aérea }(\mathrm{g})\end{array}$} & Média \\
\hline & $\mathrm{EF}$ & EQ & & $\mathrm{EF}$ & $\mathrm{EQ}$ & \\
\hline Ágar & $2,33 \mathrm{~A} \mathrm{ab}$ & $2,34 \mathrm{~A} \mathrm{a}$ & 2,33 & $0,16 \mathrm{~A} \mathrm{ab}$ & $0,18 \mathrm{~A} \mathrm{a}$ & 0,17 \\
\hline Amido de milho & $2,86 \mathrm{~A} \mathrm{a}$ & $1,81 \mathrm{~B} \mathrm{a}$ & 2,33 & $0,22 \mathrm{~A} \mathrm{a}$ & $0,13 \mathrm{~B}$ a & 0,17 \\
\hline Ágar + Amido de Milho & $2,00 \mathrm{~A} \mathrm{~b}$ & $2,37 \mathrm{~A} \mathrm{a}$ & 2,18 & $0,13 \mathrm{~A} \mathrm{~b}$ & $0,17 \mathrm{~A} \mathrm{a}$ & 0,15 \\
\hline Média & 2,39 & 2,17 & & 0,17 & 0,16 & \\
\hline $\mathrm{CV}(\%)$ & & & & & & \\
\hline \multirow[t]{2}{*}{ Agente Geleificante } & \multicolumn{2}{|c|}{$\begin{array}{c}\text { Massa da Matéria Seca da Raiz } \\
(\mathrm{g})\end{array}$} & Média & \multicolumn{2}{|c|}{$\begin{array}{c}\text { Massa da Matéria Seca } \\
\text { Total }(\mathrm{g})\end{array}$} & \multirow[t]{2}{*}{ Média } \\
\hline & $\mathrm{EF}$ & EQ & & EF & $\mathrm{EQ}$ & \\
\hline Ágar & $0,05 \mathrm{~A} \mathrm{a}$ & $0,06 \mathrm{~A} \mathrm{a}$ & 0,05 & $0,20 \mathrm{~A} \mathrm{ab}$ & $0,24 \mathrm{~A} \mathrm{a}$ & 0,22 \\
\hline Amido de milho & $0,06 \mathrm{~A} \mathrm{a}$ & $0,04 \mathrm{~A} \mathrm{a}$ & 0,05 & $0,28 \mathrm{~A} \mathrm{a}$ & $0,18 \mathrm{~B} \mathrm{a}$ & 0,23 \\
\hline Ágar + Amido de Milho & $0,05 \mathrm{~A} \mathrm{a}$ & $0,05 \mathrm{~A} \mathrm{a}$ & 0,05 & $0,18 \mathrm{~A} \mathrm{~b}$ & $0,22 \mathrm{~A} \mathrm{a}$ & 0,20 \\
\hline Média & 0,05 & 0,05 & & 0,22 & 0,21 & \\
\hline $\mathrm{CV}(\%)$ & \multicolumn{2}{|c|}{38,56} & \multicolumn{3}{|c|}{38,12} & \\
\hline
\end{tabular}

Médias seguidas pelas mesmas letras maiúsculas na horizontal e minúsculas na vertical não diferem entre si, pelo teste de Tukey, a $5 \%$ de probabilidade. EF: esterilização física; EQ: esterilização química. 


\section{REFERÊNCIAS}

COSTA, F.H.S.; PEREIRA, M.A.A.; OLIVEIRA, J.P.; PEREIRA, J.E.S. Efeito de agentes geleificantes alternativos no meio de cultura no cultivo in vitro de abacaxizeiro e bananeira. Ciência Agrotécnica, Lavras, v. 31, n. 1, p. 41-46, 2007.

CRUZ, C.D. Programa Genes - Estatística experimental e matrizes. Viçosa: Editora UFV, 2006. 285 p.

ERIG, A.C.; SCHUCH, M.W.; SILVA, L.C. Multiplicação in vitro de macieira (Malus domestica Borkh) cv. Galaxy: meio de cultura e agentes solidificantes alternativos. Revista Brasileira de Agrociência, Pelotas, v. 10, n. 3, p. 297-302, 2004.

FAO. FAOSTAT. Agricultural statistics database: world agricultural information center: 2012. Disponível em: $<$ http://faostat3.fao.org/home/index. html\#HOME>. Acesso em: 25 jun. 2013.

FERRI, V.C.; CENTELLAS, A.Q.; HELBIG, V.E.; FORTES, G.R.L. Uso do ágar, amido e ácido indolbutírico no enraizamento in vitro do portaenxerto de macieira MM111. Revista Ciência Rural, Santa Maria, v. 28, n. 4, p. 561-565, 1998.

IBGE. SIDRA. Quadro comparativo de produção de abacaxi. 2012. Disponível em: $\leq$ http://www.sidra. ibge.gov.br>. Acesso em: 25 jun. 2013.

MURASHIGE, T.; SKOOG, F. A revised medium for rapid growth and bioassays with tobacco tissue cultures. Physiologia Plantarum, Copenhagen, v. 15, p. 473-497, 1962.

OLIVEIRA, R.S. Comparação do desenvolvimento de mudas de abacaxizeiros 'Vitória' e 'Gold' em meios de cultivo econômicos. 2012.45 f. Monografia (Graduação em Agronomia) - Universidade Estadual do Norte Fluminense Darcy Ribeiro, Campos dos Goytacazes, 2012.

PEREIRA, M.R. Simplificação de meios de cultivo para propagação vegetativa in vitro do abacaxizeiro 'Vitória'. 2011. 41 f. Monografia (Graduação em Agronomia) - Universidade Estadual do Norte Fluminense Darcy Ribeiro, Campos dos Goytacazes, 2011.
REINHARDT, D.H.R.; CUNHA, G.A.P. A propagação do abacaxizeiro. 2. ed. Brasília: Embrapa Informação Tecnológica, 2006. 59 p.

RESH, H. Hydroponic food productions. $5^{\text {th }}$ ed. California: Woodbridge Press Publishing Company, 1997. 527p.

RIBEIRO, J. M.; TEIXEIRA, S.L. Multiplicação de Sequoia sempervirens em meio de cultura esterilizado com hipoclorito de sódio. Revista Brasileira de Horticultura Ornamental, Brasília, v. 13, p. 356, 2007.

SAWANTE, R.A.; TAWAR, P.N. Use of sodium hypochlorite as media sterilant in sugarcane micropropagation at commercial scale. Sugar Technology, Amsterdam, v. 13, n. 1, p. 27-35, 2011.

SOUZA, A.S.; JUNGHANS, T.G. Introdução à micropropagação de plantas. Cruz das Almas: Embrapa Mandioca e Fruticultura Tropical, 2006. $152 \mathrm{p}$.

TEIXEIRA, S.L.; RIBEIRO, J.M.; TEIXEIRA, M.T. Influence of $\mathrm{NaClO}$ on nutrient medium sterilization and on pineapple (Ananas comosus cv. Smooth Cayenne) behavior. Plant Cell Tissue Organ Culture, Boston, v. 86, p. 375-378, 2006.

TEIXEIRA, S.L.; RIBEIRO, J.M.; TEIXEIRA, M.T. Utilização de hipoclorito de sódio na esterilização de meio de cultivo para multiplicação in vitro de Eucalyptus pellita L. Ciência Florestal, Santa Maria, v. 8, n. 2, p.185-191, 2008.

TIWARI, A.K.; TRIPATHI, S.; LAL, M.; MISHRA, S. Screening of some chemical disinfectants for media sterilization during in vitro micropropagation of sugarcane. Sugar Technology, Amsterdam, v. 14, n. 4, p.364-369, 2012.

VENTURA, J.A.; COSTA, H.; CAETANO, L.C.S. Abacaxi 'Vitória': uma cultivar resistente à fusariose. Revista Brasileira de Fruticultura, Jaboticabal, v. 31, n. 4, p. 931-1233, 2006. 